\title{
Inflation Dynamics and the Cost Channel of Monetary Transmission ${ }^{1}$
}

\author{
Ibrahim Chowdhury, ${ }^{2}$ Mathias Hoffmann, ${ }^{3}$ \\ and Andreas Schabert ${ }^{4}$ \\ University of Cologne
}

This version: October 14, 2003

\begin{abstract}
Evidence from vector autoregressions indicates that the impact of interest rate shocks on macroeconomic aggregates can substantially be affected by the so-called cost channel of monetary transmission. In this paper we apply a structural approach to examine the relevance of the cost channel for inflation dynamics in G7 countries. We augment the so-called hybrid New Keynesian Philips curve by letting firms' costs for external funds rise with the short-run nominal interest rate. Our estimates reveal that the magnitude of this cost channel strongly varies between countries, including member countries of the EMU, in accordance with differences in their financial systems. Simulations of a New Keynesian model further show that the presence of the cost channel substantially affects the transmission of monetary policy shocks, in particular, the inflation response.

JEL classification: E31, E32, E52

Keywords: Inflation Dynamics, New Keynesian Phillips Curve, External Financing, Monetary Transmission.
\end{abstract}

\footnotetext{
${ }^{1}$ The authors would like to thank Matthew Canzoneri, Dale Henderson, Jürgen von Hagen, Ludger Linnemann, Carl Walsh, Axel Weber, and participants of the ZEI Summer School 2003 for helpful comments and suggestions. They are further indebted to Pierpaolo Benigno for the data.

${ }^{2}$ Corresponding author: University of Cologne, Department of Economics, 50931 Cologne, Germany, Email: i.chowdhury@wiso.uni-koeln.de, fax: +49/221/470-5024, tel: +49/221/470-6066.

${ }^{3}$ University of Cologne, Department of Economics, Email: m.hoffmann@wiso.uni-koeln.de.

${ }^{4}$ University of Cologne, Department of Economics, Email: schabert@wiso.uni-koeln.de.
} 


\section{Introduction}

This paper aims at revealing whether costs of external funds affect pricing decisions of firms and thus matter for inflation dynamics in the G7 countries. While financial markets are already considered in various studies focussing on the transmission of monetary policy shocks, i.e., in the literature on the so-called 'credit channel', their impact on inflation dynamics within the New Keynesian approach, which by now serves as the predominant framework for monetary policy analysis, has rarely been taken into account. ${ }^{5}$ Recent empirical contributions to this literature based on the New Keynesian Phillips curve presume that price rigidities are the main source for monetary non-neutrality and structural price adjustments solely stem from changes in factor remunerations (see e.g., Galí and Gertler, 1999, Galí et al., 2001). Hence, monetary policy actions only affect inflation dynamics via changes in labor costs brought about by shifts in aggregate demand, predicting synchronous responses of output and prices to interest rate shocks.

Though these predictions regarding price responses accord to common priors about monetary policy effects, they are hardly consistent with vector autoregression (VAR) based evidence, indicating that this approach to inflation dynamics does not seem to capture the entire transmission process. In particular, as recently shown by Barth and Ramey (2001) for US data, the impact of interest rate shocks on prices and real activity is substantially affected by changes in the cost of external funds, i.e., by the 'cost-channel of monetary transmission'. Given that an interest rate hike directly raises firms' costs of external funds, the cost alleviating effect of the decline in aggregate demand is counteracted. ${ }^{6}$ Thus, the inflation response to an interest rate shock is mitigated, whereas the output response is amplified by the cost channel. While the existence of borrowing cost effects seems to be doubtless, the apparent question is, whether its impact on macroeconomic aggregates and, in particular, on inflation dynamics is in fact of measurable size.

Ravenna and Walsh (2003) have already taken a first major step in disclosing the role of the cost channel for US inflation dynamics. ${ }^{7}$ Applying a purely forward looking Phillips curve, their estimates indicate that this channel indeed significantly contributes to the evolution of inflation rates. Motivated by their findings and the estimates from Galí et al. (2001) and

\footnotetext{
${ }^{5}$ In the contemporary monetary business cycle theory financial markets are commonly presumed to be perfect. Exceptions are, for example, limited participation models (see Christiano et al., 1997), or models with segmented markets (see Alvarez et al., 2001).

${ }^{6}$ In fact the latter can even be superimposed, giving rise to an inverse price response, which is also known as the 'price puzzle' (see Sims, 1991).

${ }^{7}$ Christiano et al.'s (2001) estimation of a general equilibrium model also supports the existence of the cost channel in the US.
} 
Benigno and López-Salido (2002), which suggest that European inflation dynamics display strong backward looking elements, we extend this line of research by estimating hybrid New Keynesian Phillips curves for the G7 countries. Herein, we find that changes in short-run nominal interest rates significantly affect the evolution of inflation rates in France, Germany, Italy, Japan and the US, while we could not establish a significant cost channel in Canada and in the UK. The strength of the cost channel in the former set of countries is found to vary in accordance with differences in financial systems. The magnitude of direct interest rate effects on inflation not only relates to firms' dependence on external funds but also on the pass-through of interest rate changes. Consistent with broad evidence on differences in financial structures (see e.g., Allen and Gale, 2000), the effects of the cost channel are found to be less pronounced in continental European countries than in the US.

By integrating working capital in an otherwise standard New Keynesian model we aim at quantifying the impact of the cost channel for the transmission of shocks to a simple Taylortype interest rate rule. As emphasized in Barth and Ramey (2001), the cost channel drives a wedge between the responses of output and inflation to an interest rate shock. Applying the estimated parameter values, our simulation results indicate that the consideration of the cost channel substantially alters the inflation path. For the US, for example, the half life of the peak in the inflation response rises by one third and the initial response of inflation is mitigated by almost a half. Variations in cost channel effects for Germany, France, and Italy and, especially, for the UK reveal that heterogeneous financial structures can lead to major differences in the transmission of policy shocks. ${ }^{8}$ Hence, a convergence of financial systems seems to be an important prerequisite for a successful common monetary policy. Otherwise, the varying magnitude of direct cost effects and the induced asymmetry between inflation and output responses can substantially burden a monetary union.

The remainder is set out as follows. Section 2 develops the model. The empirical evidence is presented in Section 3. Section 4 illustrates the effects of interest rate shocks based on the estimated parameter values. Section 5 concludes.

\section{The model}

In this section we develop a simple sticky price model, that is augmented by a cost channel of monetary transmission. Throughout the paper nominal (real) variables are denoted by uppercase (lower-case) letters. There is a continuum of identical and infinitely lived households of

\footnotetext{
${ }^{8}$ See Hofmann (2003) and Mojon (2000) for evidence on heterogenous interest rate pass-through in European countries.
} 
measure one. The objective of a representative household is given by:

$$
E_{0} \sum_{t=0}^{\infty} \beta^{t}\left[(1-\sigma)^{-1} c_{t}^{1-\sigma}-\left(1+\sigma_{l}\right)^{-1} l_{t}^{1+\sigma_{l}}\right], \quad \text { with } \sigma, \sigma_{l}>0
$$

where $c$ denotes consumption, $l$ working time, $\beta \in(0,1)$ the subjective discount factor, and $E_{0}$ the expectation operator conditional on the information in period 0 . At the beginning of period $t$, households are endowed with cash $M_{t}$ and government bond holdings $B_{t}$. Before households enter the goods market, they deposit funds $D_{t}$ at financial intermediaries. Following Christiano et al. (1997), consumption expenditures are restricted by the following liquidity constraint:

$$
P_{t} c_{t} \leq M_{t}-D_{t}+P_{t} w_{t} l_{t}+P_{t} \tau_{t}
$$

where $w$ denotes the real wage, $P$ the aggregate price level and $\tau$ a lump-sum government transfer. The representative household owns the firms and the intermediaries and receives the respective profits $P \omega^{f}$ and $P \omega^{b}$. The household's budget constraint is given by

$$
B_{t+1}+M_{t+1}+D_{t}+P_{t} c_{t} \leq\left(1+i_{t}\right) B_{t}+M_{t}+\left(1+i_{t}^{d}\right) D_{t}+P_{t} w_{t} l_{t}+P_{t} \tau_{t}+P_{t} \omega_{t}^{f}+P_{t} \omega_{t}^{b}
$$

where $i\left(i^{d}\right)$ denotes the nominal interest rate on bonds (deposits). Maximizing the objective given in (1) subject to the cash constraint (2), the budget constraint (3), and a no-Ponzi-game condition, $\lim _{i \rightarrow \infty} E_{t+i}\left(B_{t+i}+M_{t+i}\right) \Pi_{v=1}^{i}\left(1+i_{t+v}\right)^{-1} \geq 0$, for given initial values $M_{0}$ and $B_{0}$, leads to the following first order conditions:

$$
\begin{aligned}
c_{t}^{-\sigma} & =\lambda_{t}+\eta_{t}, \quad\left(\lambda_{t}+\eta_{t}\right) w_{t}=l_{t}^{\sigma_{l}}, \\
\frac{1}{\beta} \lambda_{t} & =E_{t}\left[\frac{1}{\pi_{t+1}}\left(\lambda_{t+1}+\eta_{t+1}\right)\right], \quad \frac{1}{\beta} \lambda_{t}=E_{t}\left[\frac{\left(1+i_{t+1}\right)}{\pi_{t+1}} \lambda_{t+1}\right], \quad i_{t}^{d} \lambda_{t}=\eta_{t},
\end{aligned}
$$

and $0=\eta_{t}\left(m_{t}-d_{t}+w_{t} l_{t}+\tau_{t}-c_{t}\right)$ with $\eta_{t} \geq 0$ and $m_{t}-d_{t}+w_{t} l_{t}+\tau_{t}-c_{t} \geq 0$, the budget constraint (3) holding with equality and the transversality condition $\lim _{i \rightarrow \infty} E_{t} \lambda_{t+i} \beta^{t+i}\left(B_{t+i}+\right.$ $\left.M_{t+i}\right) / P_{t+i}=0$, where $\lambda$ denotes the shadow price of wealth and $\eta$ the multiplier on the cash constraint.

The final consumption good is an aggregate of differentiated goods, produced by monopolistically competitive firms indexed with $i \in[0,1]$. The CES aggregator of differentiated goods is defined as $y_{t}^{(\epsilon-1) / \epsilon}=\int_{0}^{1} y_{i t}^{(\epsilon-1) / \epsilon} d i$, with $\epsilon>1$, where $y$ is the number of units of the final good, $y_{i}$ equals the amount produced by firm $i$, and $\epsilon$ reflects the constant elasticity of substitution between these differentiated goods. Let $P_{i}$ and $P$ denote the price of good $i$ set by firm $i$ and the price index for the final good. The cost minimizing demand for each differentiated good is then $y_{i t}=\left(P_{i t} / P_{t}\right)^{-\epsilon} y_{t}$, with $P_{t}^{1-\epsilon}=\int_{0}^{1} P_{i t}^{1-\epsilon} d i$. The production function 
of a firm $i$ is given by: $y_{i t}=l_{i t}^{1-\alpha}$. We assume that firms have to pay wages in advance, i.e., before they sell their goods, such that they rely on external funds to run the production. In particular, firm $i$ is assumed to borrow the amount $Z_{i}$ from financial intermediaries at the beginning of the period. The corresponding liquidity constraint reads: $Z_{i t} \geq P_{t} w_{t} l_{i t}$.

After the goods are produced and sold, firms repay the loans at the end of the period at the gross nominal interest rate $\left(1+i^{l}\right)$. Hence, these loans are traded within a period and are not accumulated. Accordingly, total costs of firm $i$ in period $t$ consist of wages $P_{t} w_{t} l_{i t}$ and interest payments on loans $i_{t}^{l} Z_{i t}$. Cost minimization with respect to labor demand and wages subject to $y_{i t}=l_{i t}^{1-\alpha}$ and to the liquidity constraint for given aggregate prices then requires

$$
\left(1+i_{t}^{l}\right) w_{i t}=m c_{i t}(1-\alpha) \frac{y_{i t}}{l_{i t}}
$$

As can be seen from (5), real marginal costs $m c$ increase with the lending rate $i^{l}$. We further introduce a nominal stickiness in form of staggered price setting as developed by Calvo (1983). Allowing for a backward looking component of price setting firms, we follow Galí et al. (2001) in that aggregate supply is constrained by the so-called hybrid New Keynesian Phillips curve

$$
\widehat{\pi}_{t}=\gamma_{f} E_{t} \widehat{\pi}_{t+1}+\gamma_{b} \widehat{\pi}_{t-1}+\chi \widehat{m c}_{t}
$$

where $\widehat{x}$ denotes the percent deviation from the steady state value $\bar{x}$ of a generic variable $x, \widehat{x}=\log \left(x_{t}\right)-\log (\bar{x})$ and $\gamma \equiv \phi+\omega[1-\phi(1-\beta)], \gamma_{f} \equiv \beta \phi / \gamma, \gamma_{b} \equiv \omega / \gamma, \chi \equiv(1-$ $\omega)(1-\phi)(1-\beta \phi) \xi \gamma^{-1}$, and $\xi \equiv \frac{1-\alpha}{1+\alpha(\epsilon-1)}$, where $1-\phi$ denotes the probability for price adjustments and $\omega$ the share of firms which are assumed to adjust their prices according to the lagged inflation rate.

We assume that financial intermediaries are perfectly competitive. They receive deposits $D_{t}$ from households and supply loans $Z_{t}$ to the firms at the gross nominal interest rate $1+i_{t}^{l}$. At the end of each period, deposits $D_{t}$ together with the interest $i_{t}^{d} D_{t}$ are repaid to the households. Any profits are paid to he owners, i.e., the households. To facilitate varying degrees of interest rate changes to affect firms' costs of lending, we allow for a rigidity in the price for external funds. Rather than introducing an explicit microfoundation we assume for simplicity that this friction can be measured by a function $\Psi_{t}$, which depends on the current risk-free interest rate, $\Psi\left(R_{t}\right)$. The risk-free interest rate $R_{t} \equiv 1+i_{t}$ is taken as given for a single bank. Log-linearizing the banks' first order condition then leads to

$$
\widehat{R}_{t}^{l}=\left(1+\psi_{R}\right) \widehat{R}_{t}
$$

where $\psi_{R} \equiv \Psi_{R} R / \Psi$ and we already used that $R_{t}^{d}=R_{t}$ holds. A negative value for $\psi_{R}$ 
indicates that a change in the risk-free interest rate is not completely passed through to the lending rate, which can be rationalized by loan price rigidities (see e.g., Hannan and Berger, 1991), and mitigates the cost channel. When, on the other hand, $\psi_{R}$ is positive a rise in $R_{t}$ is even accelerated, such that the lending rate rises by more than one for one. This can be viewed as a reduced form relation based on financial market imperfections due to asymmetric information, as accentuated in the literature on the so-called financial accelerator (see Bernanke et al., 1999).

The public sector consists of a monetary and a fiscal authority. The central bank is assumed to set the nominal interest rate according to the following simple Taylor-type interest rate rule

$$
\widehat{R}_{t}=\rho_{\pi} \widehat{\pi}_{t}+\varepsilon_{t}, \quad \text { with } \rho_{\pi} \geq 0,
$$

and the innovation $\varepsilon_{t}$, which has an expected value of zero and is serially uncorrelated. The flow budget constraint of the public sector is given by $M_{t+1}-M_{t}+B_{t+1}-R_{t} B_{t}=$ $P_{t} \tau_{t}$. Fiscal policy is assumed to ensure public sector solvency, i.e., to satisfy $\lim _{i \rightarrow \infty}\left(B_{t+i}+\right.$ $\left.M_{t+i}\right) E_{t+i} \Pi_{v=1}^{i}\left(1+i_{t+v}\right)^{-1}=0$. In particular, we assume that the net supply of government bonds equals zero.

In equilibrium the set of conditions $(4), c_{t}=m_{t+1}$, the optimal pricing condition approximated by (5), (6), $y_{t}=l_{t}^{1-\alpha},(7),(8)$, and $y_{t}=c_{t}$ are satisfied. For the local analysis of the model, we apply a log-linear approximation of the equilibrium condition at the steady state with an inflation rate $\bar{\pi} \geq \beta$. Reducing the set of equilibrium conditions then allows to define the model as follows: A rational expectations equilibrium of the linear approximation to the model at the steady state is a set of sequences $\left\{\widehat{\pi}_{t}, \widehat{y}_{t}, \widehat{R}_{t}\right\}_{t=0}^{\infty}$ satisfying (8),

$$
\begin{aligned}
\widehat{\pi}_{t} & =\gamma_{f} E_{t} \widehat{\pi}_{t+1}+\gamma_{b} \widehat{\pi}_{t-1}+\gamma_{R} \widehat{R}_{t}+\gamma_{y} \widehat{y}_{t}, \\
\sigma \widehat{y}_{t} & =\sigma E_{t} \widehat{y}_{t+1}-\widehat{R}_{t}+E_{t} \widehat{\pi}_{t+1}
\end{aligned}
$$

where $\gamma_{R} \equiv \chi\left(1+\psi_{R}\right), \gamma_{y} \equiv \chi\left(\frac{\alpha}{1-\alpha}+\vartheta^{-1}\right)$, and $\vartheta^{-1}=\sigma+\sigma_{l}(1-\alpha)^{-1}$. Note that the composite coefficient $\gamma_{R}$ depends on the elasticity $\psi_{R}$, which serves as a measure for financial market rigidities. Hence, for a given degree of price rigidity $\chi$ a lower value for $\gamma_{R}$ indicates that the cost channel is - ceteris paribus - less pronounced due to an incomplete interest rate pass-through. Further, note that the model is not entirely forward looking, as the lagged inflation rate enters the aggregate supply constraint. Accordingly, inflation is allowed to recover smoothly in response to an interest rate shock. 


\section{Empirical analysis}

In this section we provide empirical evidence on the existence of the cost channel of monetary transmission in G7-countries. Prior to presenting and discussing our empirical findings, we briefly summarize some relevant financial market characteristics.

Financial structure and interest rate pass-through The direct effect of the nominal interest rate on firms' costs and their price setting behavior relies on external funds for production outlays. Hence, changes in the nominal interest rate should be less important for firms which are mainly financed internally. While the capital structure varies between individual firms and is often related to their size or industry, the overall financial structure of an economy is crucial for the macroeconomic relevance of the cost channel. Accordingly, we expect countries in which firms are known to be strongly externally financed, as for example Germany, Japan or the US (see Allen and Gale, 2000, Barth and Ramey, 2001), to exhibit a measurable impact of changes in the costs for external funds on firms' price setting behavior. Conversely, in countries where firms are primarily financed through internal sources, such as the UK (see Mayer, 1990, and Corbett and Jenkinson, 1996, 1997), direct interest rate effects on inflation should be less pronounced.

While external financing is a prerequisite for the cost channel, the pass-through from money market rates to lending rates decides on the magnitude how changes in the nominal interest rate translate to changes in firms' costs. Hence, for a low interest rate pass-through the impact of nominal interest rate changes on firms' costs should be less pronounced. Given that the interest rate pass-through can be weakend under a highly regulated or less competitive banking sector (see Hannan and Berger, 1991), we expect a dampened cost channel for continental European countries, and herein for Germany more than for France (see Mojon, 2000). In contrast, a high degree of financial market liberalization and securitization, as for example in the US (see Allen and Gale, 2000), as well as a pronounced dependence of firms on marketable debt instruments should lead to a high interest rate pass-through. Concisely, the impact of interest rate variations on firms' costs and finally on price adjustments should not only depend on the ratio of external to internal funds, but also on the prevailing interest rate pass-through.

Interest rate changes and inflation dynamics We provide single equation estimates for the so-called New Keynesian Phillips curve, which has recently been found to serve as an useful description for inflation dynamics in the US and in several European countries (see Galí and Gertler, 1999 and Galí et al., 2001). In particular, we estimate the aggregate supply constraint given in (9), that deviates from the standard New Keynesian Phillips curve, firstly, 
by considering lagged inflation rates, and, secondly, by allowing for the short-run nominal interest rate to exert a direct effect on current inflation. While the former feature, which leads to the so-called hybrid form, has already been found to significantly contribute to inflation dynamics in several countries (see, for example, Galí et al., 2001; Beningo and López-Salido, 2002), the latter has - by now - only been considered by Ravenna and Walsh's (2003), who estimate a purely forward looking Phillips curve for the US and provide significant evidence in favor of a cost channel.

By combining these two approaches, we provide international evidence for the cost channel based on hybrid New Keynesian Phillips curves. To facilitate comparisons, we first estimate a standard New Keynesian Phillips curve: ${ }^{9}$

$$
\pi_{t}=\gamma_{b} \pi_{t-1}+\gamma_{f} E_{t} \pi_{t+1}+\delta_{1} \Delta w_{t}+u_{t}
$$

Equation (11) relates inflation, $\pi_{t}$, to lagged inflation, anticipated future inflation and contemporary wage inflation, $\Delta w_{t} \equiv\left(w_{t}-w_{t-1}\right) / w_{t}$. According to (11) inflation dynamics are mixed by a backward looking and forward looking component.

As has been shown in Section 2, firms' real marginal costs may depend on the nominal interest rate, if they ought to pay wages in advance. Thus, firms have to raise external funds such that changes in the nominal interest rate affect inflation dynamics, as implied by (9). We explicitly test for the presence of such a cost channel by augmenting the standard Phillips curve, such that inflation is now also related to changes in the nominal interest rate, $\Delta R_{t} \equiv R_{t}-R_{t-1}$ :

$$
\pi_{t}=\tilde{\gamma}_{b} \pi_{t-1}+\tilde{\gamma}_{f} E_{t} \pi_{t+1}+\tilde{\delta}_{1} \Delta w_{t}+\tilde{\delta}_{2} \Delta R_{t}+v_{t}
$$

Both equations (11) and (12) are estimated applying quarterly time series data obtained from the OECD Business Sector database, the IMF's International Financial Statistics (IFS) database, and the Bureau of Labor Statistics. Phillips curve estimations are carried out for Canada, France, Germany, Italy, Japan, the UK, and the US. Hereby, inflation is generally measured using the GDP deflator. ${ }^{10}$ Real wages are constructed as the ratio of total real compensation to total employees. As a measure for short-run nominal interest rates we use three-month treasury bill rates in our estimations. ${ }^{11}$ The overall sample period spans the

\footnotetext{
${ }^{9}$ Though, similar specifications have already been estimated, as, for example, by Galí and Gertler (1999), Galí et al. (2001), and Beningo and López-Salido (2002), we apply a broader set of countries resulting in new estimates.

${ }^{10}$ For Japan and Canada data on GDP deflator were not available and inflation was therefore measured using the consumer price index.

${ }^{11}$ Due to data unavailability we use the money market rate in the case of Japan.
} 
time interval 1972-1997, excluding the recent past, where financial structures in European countries might already have gone through a further convergence process and Japan has experienced a full-blown banking crisis. The investigated sample period, however, differs slightly across the seven countries in that the starting period varies for some countries. ${ }^{12}$

Estimations are carried out using generalized methods of moments (GMM) and, hence, for the vector of instruments, $\mathbf{z}_{t}$, a set of orthogonality conditions hold. Consequently, equations (11) and (12) can be written as

$$
\begin{array}{r}
E_{t}\left\{\left(\pi_{t}-\gamma_{b} \pi_{t-1}-\gamma_{f} \pi_{t+1}-\delta_{1} \Delta w_{t}\right) \mathbf{z}_{t}\right\}=0, \\
E_{t}\left\{\left(\pi_{t}-\tilde{\gamma}_{b} \pi_{t-1}-\tilde{\gamma}_{f} \pi_{t+1}-\tilde{\delta}_{1} \Delta w_{t}-\tilde{\delta}_{2} \Delta R_{t}\right) \mathbf{z}_{t}\right\}=0 .
\end{array}
$$

In both specifications our vector of instruments, $\mathbf{z}_{t}$, includes four lags of price and wage inflation and four lags of interest rate changes. As there is considerable support for the view that the Bank of Japan regards the exchange rate as an implicit policy target (see Glick and Hutchison, 1994), we extend our set of instruments for Japan by including lagged changes of the nominal US dollar exchange rate. ${ }^{13}$ Since not all current information may be available to the public at the time they form expectations, contemporary variables are not used as instruments.

Table 1 summarizes the estimation results of the standard Phillips curve (11). We refer to these coefficient estimates as 'reduced-form' estimates. ${ }^{14}$ Given that we are predominantly interested in the (relative) importance of the cost channel, we abstain from estimating structural parameters, which are, for example, presented in Galí et al. (2001). In general, the estimated coefficients are of the right sign and are found to be statistically significant, consistent with related estimates for the hybrid Phillips curve. For the majority of the investigated countries - Canada, France, Italy, Japan, and the UK - the estimated backward looking coefficient appears to play a more pronounced role than the estimated forward looking coefficient. ${ }^{15}$ Consistent with the theoretical model changes in real wages are generally

\footnotetext{
${ }^{12}$ For the UK and France the sample period starts in 1972, while for Germany the beginning period is 1977. In the remaining four countries the sample period starts in 1979.

${ }^{13}$ In an empirical study Hutchison (1988) points towards the nominal exchange rate as an important control variable for the monetary authority in Japan. Glick and Hutchison (1994) argue that the Japanese exchange rate vis-à-vis the US dollar is an integrated part of the monetary policy objective, which in turn may have implications for the transmission mechanism of monetary policy.

${ }^{14}$ All estimated coefficients reported in Table 1 and Table 2 are Newey-West corrected to take into account possible serial correlation of the residuals.

${ }^{15}$ Estimating a hybrid marginal cost based Phillips curve over a similar sample period Beningo and LopezSalido (2002) report qualitatively similar findings for France and Italy. In the case of Germany, however, they find no evidence of backward lookingness, whereas our results indicate the presence of significant backwardlooking behavior.
} 
found to have a positive and statistically significant impact on price inflation. The largest impact of wage inflation on price inflation, measured by $\tilde{\delta}_{1}$, is observed for France, while the smallest impact can be observed in Germany and the US. In the case of Japan we do not find a positive and statistically significant coefficient on wage inflation. The estimated average coefficient on wage inflation across the European countries is found to be almost twice as large as in the US.

Table 1: Estimates of the Standard Phillips-Curve

\begin{tabular}{|c|c|c|c|c|}
\hline & $\gamma_{b}$ & $\gamma_{f}$ & $\delta_{1}$ & $J-T e s t$ \\
\hline Canada & $\begin{array}{l}0.61 \\
(0.00)\end{array}$ & $\begin{array}{l}0.28 \\
(0.00)\end{array}$ & $\begin{array}{l}0.11 \\
(0.05)\end{array}$ & 0.46 \\
\hline France & $\begin{array}{l}0.61 \\
(0.02)\end{array}$ & $\begin{array}{l}0.19 \\
(0.00)\end{array}$ & $\begin{array}{l}0.14 \\
(0.01)\end{array}$ & 0.33 \\
\hline Germany & $\begin{array}{l}0.46 \\
(0.00)\end{array}$ & $\begin{array}{l}0.48 \\
(0.00)\end{array}$ & $\begin{array}{l}0.05 \\
(0.00)\end{array}$ & 0.27 \\
\hline Italy & $\begin{array}{l}0.57 \\
(0.00)\end{array}$ & $\begin{array}{l}0.34 \\
(0.00)\end{array}$ & $\begin{array}{c}0.08 \\
(0.01)\end{array}$ & 0.27 \\
\hline Japan & $\begin{array}{l}0.62 \\
(0.04)\end{array}$ & $\begin{array}{l}0.39 \\
(0.05)\end{array}$ & $\begin{array}{c}-0.01 \\
(0.36)\end{array}$ & 0.58 \\
\hline UK & $\begin{array}{l}0.48 \\
(0.00)\end{array}$ & $\begin{array}{c}0.37 \\
(0.00)\end{array}$ & $\begin{array}{l}0.11 \\
(0.05)\end{array}$ & 0.35 \\
\hline US & $\begin{array}{c}0.37 \\
(0.00)\end{array}$ & $\begin{array}{c}0.62 \\
(0.00)\end{array}$ & $\begin{array}{c}0.05 \\
(0.00)\end{array}$ & 0.72 \\
\hline
\end{tabular}

Notes: Figures in parentheses below coefficient estimates denote pvalues. J-Test describes a test statistic for the null hypothesis that the overidentifying restrictions are satisfied. For the latter test p-values are reported.

By allowing for short-run interest rates to additionally affect inflation dynamics, we aim to evaluate the importance of the cost channel in relation to the aggregate demand channel. Including interest rate changes in the standard Phillips curve, we expect not only to find evidence for direct interest rate effects on real marginal costs, but also to raise the overall fit of the Phillips curve by reducing the uncertainty about future inflation. The inclusion of short-term interest rates in the Phillips curve is likely to provide more information about the current stance of monetary policy, which might otherwise be, at least partly, contained in the forward looking component. We therefore expect the degree of backward- and forward lookingness and the effect of wage inflation on price inflation to change as we explicitly allow for the cost channel. 
Table 2: Estimates of the Augmented Phillips-Curve

\begin{tabular}{lllllll}
\hline \hline \multirow{2}{*}{ Canada } & 0.66 & 0.22 & 0.11 & 0.03 & 0.3 & 0.43 \\
& $\tilde{\gamma}_{b}$ & $\tilde{\gamma}_{f}$ & $\tilde{\delta}_{1}$ & $\tilde{\delta}_{2}$ & $\tilde{\delta}_{2} / \tilde{\delta}_{1}$ & $J-$ Test \\
France & 0.75 & 0.11 & 0.09 & 0.05 & 0.6 & 0.79 \\
& $(0.00)$ & $(0.03)$ & $(0.001)$ & $(0.003)$ & & \\
Germany & 0.52 & 0.40 & 0.05 & 0.04 & 0.8 & 0.37 \\
\multirow{4}{*}{ Italy } & $(0.00)$ & $(0.00)$ & $(0.02)$ & $(0.07)$ & & \\
\multirow{2}{*}{ Japan } & 0.63 & 0.25 & 0.10 & 0.08 & 0.8 & 0.62 \\
& $(0.00)$ & $(0.00)$ & $(0.01)$ & $(0.00)$ & & \\
UK & 0.49 & 0.46 & 0.06 & 0.07 & 1.2 & 0.48 \\
\multirow{2}{*}{ US } & $(0.05)$ & $(0.03)$ & $(0.01)$ & $(0.02)$ & & \\
& 0.49 & 0.37 & 0.11 & 0.02 & 0.2 & 0.35 \\
& $(0.00)$ & $(0.00)$ & $(0.05)$ & $(0.77)$ & & \\
& 0.65 & 0.33 & 0.05 & 0.06 & 1.2 & 0.54 \\
\hline
\end{tabular}

Notes: See Table 1

Table 2 reports the 'reduced-form' estimates of the augmented Phillips curve as specified in (12). Several remarkable insights emerge from this table. First, table 2 provides clear evidence in favor of a cost channel. Except for Canada and the UK, interest rate changes are always found to have a statistically significant effect on inflation. The strongest evidence for a cost channel is found in Japan and in Italy, where the coefficient $\tilde{\delta}_{2}$ takes a value of 0.07 and 0.08 , respectively. Second, by considering the cost channel we generally find the effect of wage inflation on price inflation to remain broadly unchanged (see table 1). The only exception is Japan, where the relevant coefficient is now positive in sign and also statistically significant. The column labelled $\tilde{\delta}_{2} / \tilde{\delta}_{1}$ further measures the strength of the cost channel relative to the aggregate demand channel based on point estimates. According to this measure, the former dominates the latter channel in Japan and in the US, while the opposite applies to France, Germany, and Italy. Under the augmented Phillips curve the backward-looking behavior now plays a more pronounced role in all examined countries. This holds particularly for the US. One possible explanation for this phenomenon is that by including short-term interest rates in the Phillips curve more detailed information about the current and future stance of monetary policy is now available, making the forward looking component less relevant.

As commonly known the choice of instruments is relevant for the small sample properties of the GMM estimator. The small sample bias can be large, and increasing the number of instruments can reduce the variance of the estimates. Therefore, we carried out a variety 
of robustness tests to check the appropriateness of the chosen specification. ${ }^{16}$ For example, we augmented the list of instruments by including longer-term nominal interest rates. ${ }^{17}$ The inclusion of long-term interest rates allows to extract predictions of the evolution of future interest rates, which is likely to affect a firm's refinancing strategy. Overall, the obtained results are found to be qualitatively similar to the ones previously reported in Table 1 and 2. The relevance of alternative sets of instruments has been checked by applying a F-test to verify their predictive power. In general, the F-test suggested that the inclusion of additional instruments may not be relevant, as also confirmed by the reported J-tests. As recently discussed by Guerreri (2001) and Galí, Gertler and López-Salido (2003), additional lags of inflation may enter the Phillips curve specification even if firms set prices in a forward looking manner, such that estimates of the forward looking component may be biased. We addressed this issue by allowing for additional lags of inflation in the hybrid Phillips curve. Overall, the added lags were not found to be statistically significant, indicating that our estimates of the forward looking component are not biased. In the base line case our model was estimated by a forward looking horizon of inflation of one quarter. To control for additional forward lookingness in the price setting behavior of firms we alternatively allowed for different target horizons of expected inflation. ${ }^{18}$ We found, however, that the impact of the forward looking component on contemporary inflation decreases with the target horizon and was not statistically significant in the majority of cases.

Our empirical findings point to the presence of a cost channel in France, Germany, Italy, Japan, and in the US, while in the UK and Canada the cost channel only appears to play a minor role. The impact of interest rates on firms' costs and therefore inflation seems to be of utmost importance in Japan and the US. These results are in general consistent with existing evidence on the role of external funds provided in the corporate finance literature. Corbett and Jenkinson (1997) and Mayer (1990), for example, have highlighted the importance of bank loans in Japan, whereas they report that firms are mostly internally financed in the UK. While the results for France and Germany are consistent with the strong reliance of firms on bank loans (see Allen and Gale, 2000), it does not explain the strength of the cost channel in the US. Thus, the mere amount of external funds raised by firms does not seem to be solely decisive for the strength of the direct interest rate effects. In particular, the pass-through of money market rates to lending rates or interest rates on corporate bonds in fact governs the transmission of interest rate policy via the cost channel. According to this view, the cost

\footnotetext{
${ }^{16}$ The details on the robustness analysis are available upon request.

${ }^{17}$ In particular we applied 10 year government bond yields of the countries examined.

${ }^{18}$ We specifically considered a forward looking horizon of three and six quarters.
} 
channel in the US, where a large part of external funds are raised via marketable instruments (see Gale and Allen, 2000), should be more effective than, for example, in Germany, where the interest rate pass-through is known to be sluggish due to a less competitive banking sector (Mojon, 2000) and to tight relations to firms (see Kueppers, 2001). Accordingly, the existence of the cost channel depends on the firms' dependence on external funds, while the pass-through from central bank rates to lending rates decides on the strength thereof.

\section{Monetary policy and the Cost Channel}

In this section we examine the implications of the cost channel for the conduct of monetary policy and, in particular, the transmission of interest rate shocks within our theoretical model. Before we present simulated impulse responses based on the point estimates reported in Table 2 , we provide some analytical results.

Analytical results It is well-known from the literature on interest rate policy that the interest rate response to changes in the inflation rate crucially affects the local dynamic properties of the model. While the so-called Taylor principle, $\rho_{\pi}>1$, ensures a uniquely determined equilibrium path for the standard New Keynesian model without a cost-channel (see Woodford, 2001), the presence of the latter can be shown to affect the requirements for interest rate policy to rule out self-fulfilling expectations. In particular, $\gamma_{R}>0$ leads to an additional (upper) bound for the inflation elasticity, as shown by Brueckner and Schabert (2003) for the purely forward looking case, $\gamma_{b}=0$. This principle also applies for the hybrid specification of the aggregate supply constraint, $\gamma_{b}>0$, where stability and uniqueness requires exactly one stable eigenvalue. The determinacy condition for $\gamma_{b}=0$, which exactly reads $1<\rho_{\pi}<\frac{\sigma \gamma_{R}+\gamma_{R} \sigma_{l}+\sigma(1-\beta)}{\gamma_{R} \sigma}$ (see Brueckner and Schabert, 2003), reveals that the upper bound and thus the interval for stabilizing inflation elasticities declines with the interest rate coefficient $\gamma_{R}$. Correspondingly, monetary policy gives rise to self-fulfilling expectations if the inflation elasticity is too high, i.e., if interest rate policy is too active. In this case a higher inflation rate triggers an extreme adjustment of the nominal interest rate which can further lead to a rise in the inflation rate via the cost channel if the ratio $\gamma_{R} / \gamma_{y}$ is sufficiently high.

To derive the main qualitative features regarding the transmission of interest rate shocks, we assume, for simplicity, that production is linear in labor, $\alpha=0$, prices are set in a nonbackward looking way, $\omega=0$, and the elasticity $\psi_{R}$ satisfies $\psi_{R}<\sigma_{l} / \sigma$. Subsequently, we assume interest rate policy to satisfy the requirements for real determinacy, such that the fundamental (or the minimum state) solution is the unique solution of the model. Given 
that the model then exhibits no endogenous state, the fundamental solution features a single state variable given by the innovations $\varepsilon_{t}: \widehat{\pi}_{t}=\delta_{\pi} \varepsilon_{t}$ and $\widehat{y}_{t}=\delta_{y} \varepsilon_{t}$. Applying the method of undetermined coefficients, the responses to an interest rate shock can easily be derived. The result is summarized in the following proposition.

Proposition 1 (Monetary Transmission) Suppose that a contractionary monetary policy shock hits an economy where $\omega=\alpha=0$ and $\psi_{R}<\sigma_{l} / \sigma$. Then the decline in inflation is mitigated and the decline in output is accelerated by higher values for the interest rate coefficient $\gamma_{R}$.

Proof. Applying the fundamental solution, $\widehat{\pi}_{t}=\delta_{\pi} \varepsilon_{t}$ and $\widehat{y}_{t}=\delta_{y} \varepsilon_{t}$, for the model (8)-(10) with $\omega=0$ leads to the conditions: $\sigma \delta_{y}=-\left(\rho_{\pi} \delta_{\pi}+1\right)$ and $\left(1-\gamma_{R} \rho_{\pi}\right) \delta_{\pi}=\gamma_{y} \delta_{y}+\gamma_{R}$. Eliminating $\delta_{y}$ gives $\left(1-\gamma_{R} \rho_{\pi}\right) \delta_{\pi}=\gamma_{R}-\gamma_{y}\left(\rho_{\pi} \delta_{\pi}+1\right) / \sigma$, which leads to the following solutions for $\delta_{\pi}$ and $\delta_{y}: \delta_{\pi}=-\left(\gamma_{y} \sigma^{-1}-\gamma_{R}\right)\left[1+\left(\gamma_{y} \sigma^{-1}-\gamma_{R}\right) \rho_{\pi}\right]^{-1}$ and $\delta_{y}=\left(\gamma_{y}-\sigma \gamma_{R}\right)^{-1} \delta_{\pi}$. As $\psi_{R}<\sigma_{l} / \sigma \Rightarrow \gamma_{y}>\sigma \gamma_{R}$, inflation and output decline in response to an interest rate shock, $\delta_{\pi}<0$ and $\delta_{y}<0$. It can further be seen that $\delta_{\pi}$ increases and $\delta_{y}$ decreases with $\gamma_{R}$, which establishes the claims made in the proposition.

According to the result presented in Proposition 1, a contractionary monetary policy shock leads to a more pronounced decline in real activity and a mitigated decline in inflation under the cost channel. Moreover, the impact of the cost channel is more pronounced for higher values of the elasticity $\psi_{R}$, which measures for $\psi_{R}<0$ an incomplete pass-through from official interest rates $R$ to lending rates $R_{l}$. A positive value for $\psi_{R}$ can, however, only be rationalized by imperfections in financial markets, i.e., the financial accelerator, causing banks to raise the lending rate by more than one for one with the official interest rate. Under a severe financial market friction, $\psi_{R}>\sigma_{l} / \sigma$, a positive interest rate innovation can then even lead to a rise in inflation - also known as the price puzzle. Thus, a rise in financial market frictions, raises the likelihood for the occurrence of a puzzling price behavior in response to an interest rate rule innovation. According to this mechanism, a shock to a common interest rate rule can in principle lead to opposed responses in the inflation rate in countries with different degrees of financial market frictions.

Simulations In order to quantify the contribution of the cost channel of monetary transmission to inflation dynamics, this section presents simulated responses to interest rate shocks. In particular, we derive impulse responses by applying the estimated coefficients of the aggregate supply constraint (9) presented in Section 2. To isolate the effects stemming from the cost channel of monetary transmission, we further compute responses for the case where the cost channel is assumed to be absent, by setting the coefficient $\gamma_{R}\left(\tilde{\delta}_{2}\right)$ equal to zero. 
Thereby we assume that the estimated coefficient on real wage inflation, $\gamma_{w}\left(\tilde{\delta}_{1}\right)$, takes the same value. ${ }^{19}$

The impulse responses to an interest rate shock are obtained by applying the method of undetermined coefficients (see Appendix). The solution of our model requires the identification of several parameters. For this we apply the point estimates for $\tilde{\gamma}_{b}, \tilde{\gamma}_{f}, \gamma_{w}\left(\tilde{\delta}_{1}\right)$ and $\gamma_{R}\left(\tilde{\delta}_{2}\right)$ (see 12), which are reported in Table 2. To facilitate comparisons, the parameter for the aggregate demand constraint (10) and the policy rule (8) are held constant in all cases. They are set equal to values which are commonly applied in the literature. In particular, we set the relative risk aversion and labor supply elasticity equal to two $\left(\sigma=\sigma_{l}=2\right)$ and the discount rate $\beta$ equal to 0.99 . The labor income share $1-\alpha$ and the elasticity of substitution between any two differentiated goods are assumed to equal 0.67 and 10, respectively. Since the existence of the cost channel, $\gamma_{R}\left(\tilde{\delta}_{2}\right)>0$, leads to the aforementioned additional (upper) bound for the inflation elasticity $\rho_{\pi}$, it is set to a modest value $\left(\rho_{\pi}=1.1\right)$. This leads to saddle path stability in all cases (see Appendix). By combining these parameter values the interest elasticity $\psi_{R}$ can then be determined.

As we focus on the relative importance of the cost channel for the behavior of prices and output rather than on the determination of the structural parameter underlying the aggregate supply constraint, we abstain from reporting values for the latter. Table 3 provides the impact responses of inflation, $\delta_{\pi e}$, and output, $\delta_{y e}$, to a positive innovation to the interest rate rule of equation (8). As shown in Table 3, inflation and output always decline as an initial response to a positive nominal interest rate shock. Given that $\rho_{\pi}>1$, the real interest rate rise induces households to increase their savings and to reduce consumption such that output declines. The associated decline in real wages tends to decrease real marginal costs, leading to a decline in inflation.

In accordance with Proposition 1 the initial negative output response is stronger under the cost channel, $\gamma_{R}\left(\tilde{\delta}_{2}\right)>0$. This effect is especially pronounced for France, Germany, Italy, Japan, and the US. For example, the initial output decline in the US is amplified by $10 \%$ under the cost channel, while Japan experiences a relative output loss of $13 \%$.

\footnotetext{
${ }^{19}$ Given that the empirical analysis provides similar coefficients for real wage inflation in the estimated standard and augmented Phillips curve, this assumption seems to be a suitable approximation.
} 
Table 3: Impact Multipliers (in \%) to $+\mathbf{1 \%}$ Interest Rate Innovations

\begin{tabular}{lcccc}
\hline \hline & \multicolumn{2}{c}{ Inflation $\left(\widehat{\pi}_{t}\right)$} & \multicolumn{2}{c}{ Output $\left(\widehat{y}_{t}\right)$} \\
& $\delta_{\pi e}\left(\gamma_{R}=\tilde{\delta}_{2}\right)$ & $\delta_{\pi e}\left(\gamma_{R}=0\right)$ & $\delta_{y e}\left(\gamma_{R}=\tilde{\delta}_{2}\right)$ & $\delta_{y e}\left(\gamma_{R}=0\right)$ \\
\hline Canada & -0.21 & -0.23 & -0.37 & -0.36 \\
France & -0.10 & -0.14 & -0.44 & -0.41 \\
Germany & -0.09 & -0.13 & -0.45 & -0.42 \\
Italy & -0.15 & -0.21 & -0.41 & -0.37 \\
Japan & -0.08 & -0.17 & -0.45 & -0.40 \\
UK & -0.22 & -0.24 & -0.37 & -0.36 \\
US & -0.08 & -0.13 & -0.45 & -0.41 \\
\hline
\end{tabular}

Table 3 further reveals that the presence of the cost channel can strongly extenuate the decline of inflation. Consistent with the prediction in Proposition 1, the initial decline in inflation is mitigated for more pronounced direct interest rate effects. In the US (Japan) the initial inflation response under financial market frictions is reduced by $38 \%(53 \%)$ relative to the case where the cost channel is absent. Similar findings can be established for Germany and France, where the difference in the inflation response equals $31 \%$ and $29 \%$, respectively. In contrast, the difference amounts to only $9 \%$ in Canada and $8 \%$ in the UK, where however the cost channel was found to be insignificant.

According to the estimated coefficients reported in Table 2, the relative impact of the nominal interest rate on firms' costs varies between the countries, as can be seen from the ratio of coefficients $\gamma_{R} / \gamma_{w}\left(\tilde{\delta}_{2} / \tilde{\delta}_{1}\right)$. This ratio equals 1.2 for the USA and for Japan, while it takes a much lower value, 0.8 for Germany and Italy, and 0.6 for France, indicating that the costs of external funding plays a more important role for inflation dynamics in the former countries. The strong direct impact of interest rate changes in Japan and in the US is reflected by the interest elasticity, $\psi_{R}$, which captures the amplification of money market rates. The elasticity equals 0.28 for Japan and 0.32 for the US, whereas $\psi_{R}$ equals -0.45 and -0.04 in France and Germany, respectively. While the negative values are consistent with the view that interest rate changes are not completely passed through the intermediary sector, positive values for $\psi_{R}$ can be rationalized by considering additional financial market frictions, as for example the financial accelerator (see Bernanke et al., 1999). ${ }^{20}$

\footnotetext{
${ }^{20}$ For example, time series evidence provided by Chinn and Dooley (1996) suggests that monetary transmission in Japan is accompanied by substantial credit supply effects.
} 


\section{Figure 1: Impulse Responses to Interest Rate Shocks}

(solid line: cost channel; dotted line: no cost channel)

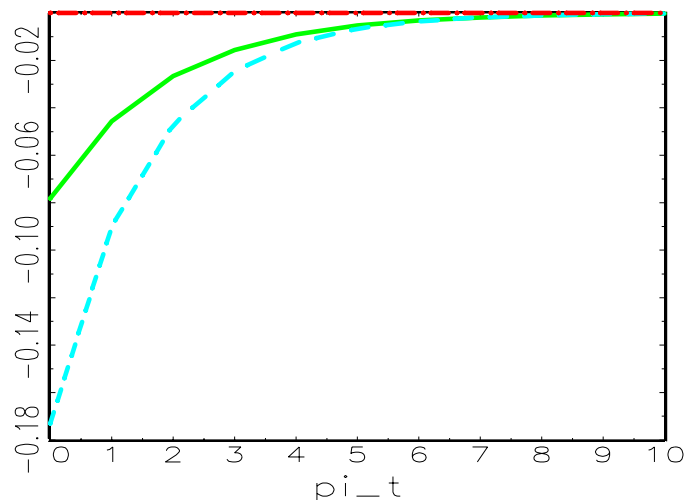

Inflation Response for Japan

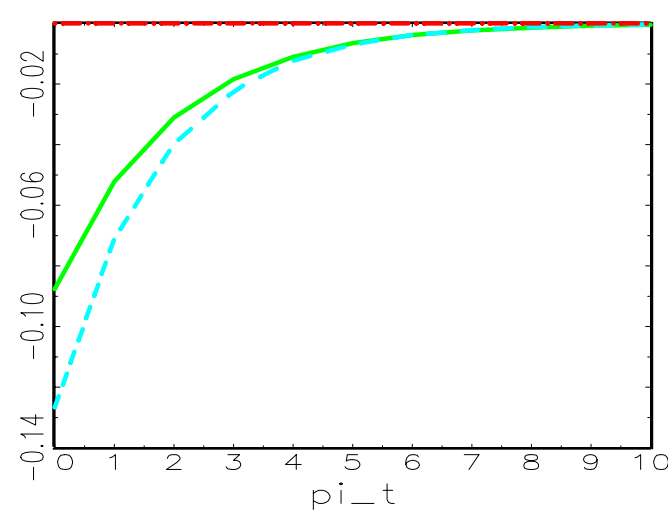

Inflation Response for Germany

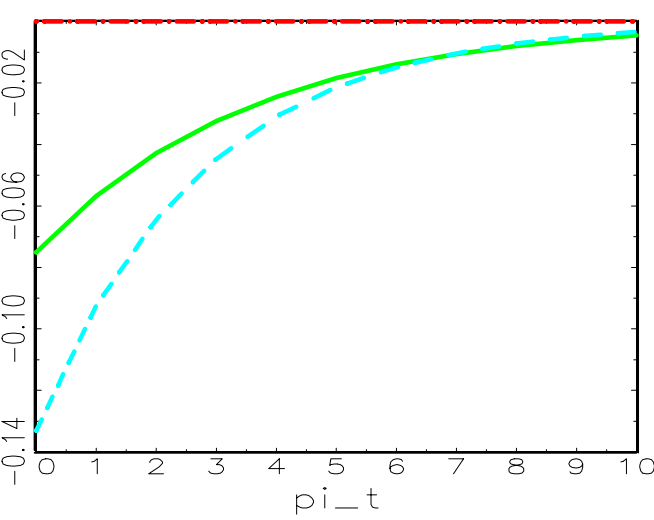

Inflation Response for the US

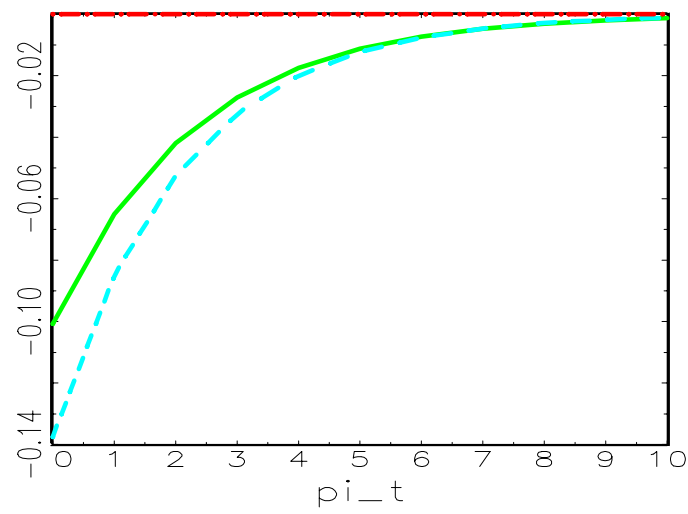

Inflation Response for France

As the model features a backward-looking component, i.e., lagged inflation rates, the impulse responses exhibit prolonged inflation dynamics. This can be seen from Figure 1, where impulse response functions of the inflation rate to a temporary monetary contraction are displayed for selected G7 countries. The solid line represents the inflation response in the case of an existing cost channel, $\gamma_{R}\left(\tilde{\delta}_{2}\right)>0$, while the dotted line reflects the response when the cost channel is not present, $\gamma_{R}\left(\tilde{\delta}_{2}\right)=0$.

The impulse response functions in Figure 1 show that a more pronounced cost channel indeed extenuates the adjustment of inflation. Accordingly, the cost channel can be viewed as a source for price reactions to interest rate shocks to be less emphasized. Measuring the persistence of the inflation response in terms of the peak's half-life highlights this argument. After an initial deviation the inflation rate of the US, for example, would return to its steady state value with a half-life of 3 periods when financial market frictions are present, while 
the half-life equals 2 periods in case where the cost channel is absent. As also stressed by Christiano et al. (2001), the direct effect of nominal interest rates on firms' costs can contribute to inflation persistence in a substantial way.

The simulations carried out in this section indicate that the strength of the cost channel, as found in the data, is indeed able to affect macroeconomic variables and, in particular, price reactions to interest rate shocks in a substantial way. Moreover, the overall pattern of the results support the view that the presence of the cost channel of monetary transmission is consistent with VAR evidence (see e.g., Christiano et al., 1999), indicating inertia in inflation and strong responses in output to a contractionary policy shock. ${ }^{21}$ Our results further reveal that the strength of the cost channel strongly varies across the G7 countries, consistent with the degree to which firms rely on external funds and the magnitude of financial market frictions. Given that the cost channel effect is opposed to the aggregate demand effect of interest rate shocks on inflation, this potentially constitutes an additional burden for a common monetary policy for countries with heterogenous financial structures.

\section{Conclusion}

When firms rely on external funds, changes in borrowing costs can affect their pricing decisions. If changes in official interest rates are further at least partially passed through to lending rates, then interest rate policy can have a direct bearing on prices via the so-called cost channel of monetary transmission. While VAR based studies already seem to support the presence of the cost channel, this paper applies a structural approach, i.e., the New Keynesian Phillips curve, and provides broad evidence in favor of the cost channel. The estimated effects of lending costs are found to substantially contribute to inflation dynamics in the majority of G7 countries. We introduce a non-zero demand for external funds by firms in a standard sticky price model, leading to a hybrid New Keynesian Phillips curve which features the short-term nominal interest rate.

Our estimates reveal significant direct interest rate effects on the inflation rate in countries where firms strongly rely on external funds, while the strength of the cost channel relates to the particular interest rate pass-through. The estimates of the aggregate supply constraint are then applied to quantify the impact of direct interest rate effects for inflation responses to an interest rate shock in a New Keynesian model. Simulations of the model reveal that the cost channel is potentially able to increase the persistence in the inflation response by one third and to mitigate the inflation response by almost a half. Hence, the cost channel effects,

\footnotetext{
${ }^{21}$ This point has already been raised by Barth and Ramey (2001).
} 
which we found to exist in several industrial countries, seem to be too large to be neglected for the assessment of the impact and therefore the efficacy of interest rate policy.

\section{Appendix: Derivation of the fundamental solution}

The model given in (8)-(10) is reduced by eliminating $R$ with (8) leading to the following set of two equations:

$$
\begin{aligned}
\sigma \widehat{y}_{t} & =\sigma E_{t} \widehat{y}_{t+1}-\rho_{\pi} \widehat{\pi}_{t}-\varepsilon_{t}+E_{t} \widehat{\pi}_{t+1} \\
\widehat{\pi}_{t}-\gamma_{R} \rho_{\pi} \widehat{\pi}_{t} & =\gamma_{f} E_{t} \widehat{\pi}_{t+1}+\gamma_{b} \widehat{\pi}_{t-1}+\gamma_{R} \varepsilon_{t}+\frac{\gamma_{w}}{\vartheta} \widehat{y}_{t} .
\end{aligned}
$$

Given that saddle path stability is ensured, the model features one stable eigenvalue, $0<$ $\delta_{\pi}<1$. Hence, the fundamental solution takes the following form:

$$
\widehat{\pi}_{t}=\delta_{\pi} \widehat{\pi}_{t-1}+\delta_{\pi e} \varepsilon_{t}, \quad \widehat{y}_{t}=\delta_{y \pi} \widehat{\pi}_{t-1}+\delta_{y e} \varepsilon_{t} .
$$

With the use of the conditions (17), equation (15) can be rewritten as $\sigma\left(\delta_{y \pi} \widehat{\pi}_{t-1}+\delta_{y e} \varepsilon_{t}\right)=$ $\sigma \delta_{y \pi}\left(\delta_{\pi} \widehat{\pi}_{t-1}+\delta_{\pi e} \varepsilon_{t}\right)-\rho_{\pi}\left(\delta_{\pi} \widehat{\pi}_{t-1}+\delta_{\pi e} \varepsilon_{t}\right)-\varepsilon_{t}+\delta_{\pi}\left(\delta_{\pi} \widehat{\pi}_{t-1}+\delta_{\pi e} \varepsilon_{t}\right)$ whereby $E_{t} \widehat{y}_{t+1}=\delta_{y \pi} \widehat{\pi}_{t}$ and $E_{t} \widehat{\pi}_{t+1}=\delta_{\pi} \widehat{\pi}_{t}$. To solve the system one has to equate all coefficients of $\widehat{\pi}_{t-1}$ and $\varepsilon_{t}$ to zero. It follows that

$$
\delta_{y \pi}=\frac{\left(\delta_{\pi}-\rho_{\pi}\right) \delta_{\pi}}{\sigma\left(1-\delta_{\pi}\right)} \quad \text { and } \quad \delta_{y e}=\sigma^{-1}\left(\delta_{\pi e}\left(\sigma \delta_{y \pi}-\rho_{\pi}+\delta_{\pi}\right)-1\right) .
$$

In the same way equation (16) becomes $\left(1-\gamma_{R} \rho_{\pi}\right)\left(\delta_{\pi} \widehat{\pi}_{t-1}+\delta_{\pi e} \varepsilon_{t}\right)=\gamma_{f} \delta_{\pi}\left(\delta_{\pi} \widehat{\pi}_{t-1}+\delta_{\pi e} \varepsilon_{t}\right)+$ $\gamma_{b} \widehat{\pi}_{t-1}+\gamma_{R} \varepsilon_{t}+\gamma_{y}\left(\delta_{y \pi} \widehat{\pi}_{t-1}+\delta_{y e} \varepsilon_{t}\right)$. Again, setting $\widehat{\pi}_{t-1}$ and $\varepsilon_{t}$ equal to zero results in

$$
\delta_{\pi}=\frac{\gamma_{b}+\gamma_{y} \delta_{y \pi}+\gamma_{f} \delta_{\pi}^{2}}{\left(1-\gamma_{R} \rho_{\pi}\right)} \quad \text { and } \quad \delta_{\pi e}=-\frac{\left(\gamma_{R}+\gamma_{y} \delta_{y e}\right)}{\gamma_{f} \delta_{\pi}-\left(1-\gamma_{R} \rho_{\pi}\right)}
$$

Eliminating $\delta_{y \pi}$ the first condition in (19) can be rewritten as $0=\gamma_{b}+\gamma_{y} \frac{\left(\delta_{\pi}-\rho_{\pi}\right) \delta_{\pi}}{\sigma\left(1-\delta_{\pi}\right)}+\gamma_{f} \delta_{\pi}^{2}-$ $\left(1-\gamma_{R} \rho_{\pi}\right) \delta_{\pi}$, which mirrors the cubic equation in $\delta_{\pi}$. For given parameter values of $\gamma_{f}$, $\gamma_{R}, \gamma_{y}=\frac{\gamma_{w}}{\vartheta}, \sigma$ and $\rho_{\pi}$ the cubic equation can be solved numerically. Saddle path stability, which is guaranteed if $1<\rho_{\pi}<\frac{\gamma_{y}+\sigma-2 \sigma \gamma_{f}}{\sigma \gamma_{R}},{ }^{22}$ ensures that there is a single stable root of this equation, which lies between zero and one. For a given value for $\delta_{\pi}$, one can easily determine the remaining coefficient $\delta_{y \pi}, \delta_{y e}$ and $\delta_{\pi e}$ from (18) and (19). Given these coefficients impulse response functions are then computed with (17).

\footnotetext{
${ }^{22}$ The proof can be made available upon request by the authors.
} 


\section{$7 \quad$ References}

Allen, F. and Gale, D., 2000, Comparing Financial Systems, MIT, Press: Cambridge.

Alvarez, F., R.E. Lucas, and W.E. Weber, 2001, Interest Rates and Inflation, American Economic Review, Papers \& Proceedings, vol. 91, 219-225.

Barth, M.J., and V., Ramey, 2000, The Cost Channel of Monetary Transmission, NBER Working Paper, no. 7675.

Benigno, P. and J.D. López-Salido, 2002, Inflation Persistence and Optimal Monetary Policy in the Euro Area, European Central Bank, Working Paper no. 178.

Bernanke, B., M. Gertler and S. Gilchrist, 1999, The Financial Accelerator in a Quantitative Business Cycle Framework, in: M. Woodford and J.B. Taylor (eds.), Handbook of Macroeconomics, North-Holland, Amsterdam, 1341-1393.

Brueckner, M., and A. Schabert, 2003, Supply Side Effects of Monetary Policy and Equilibrium Multiplicity, Economics Letters 79, 205-211.

Calvo, G., 1983, Staggered Prices in a Utility-Maximizing Framework, Journal of Monetary Economics, vol. 12, 383-398.

Chinn, M. and Dooley, M., 1996, Asia-Pacific Capital Markets: Measurement of Integration and Implications for Economic Activity, NBER Working Paper, no. 5280.

Christiano, L.J., M. Eichenbaum, and C.L. Evans, 1997, Sticky Price and Limited Participation Models of Money: A Comparison, European Economic Review, 41, 1201-49.

Christiano, J.L., M. Eichenbaum, and C.L. Evans, 1999, Monetary Policy Shocks: What Have We Learned and to What End?, in: M. Woodford and J.B. Taylor (eds.), Handbook of Macroeconomics, Amsterdam: North-Holland.

Christiano, L.J., M. Eichenbaum, and C.L. Evans, 2001, Nominal Rigidities and the Dynamic Effect of a Shock to Monetary Policy, Federal Reserve Bank of Cleveland, Working Paper 107.

Corbett, J. and Jenkinson, T.J., 1996, The Financing of Industry, 1970-89: An International Comparison, Journal of the Japanese and International Economies, vol. 10, 71-96. 
Corbett, J. and Jenkinson, T.J., 1997, How is Investment Financed? A Study of Germany, Japan, UK and US, Manchester School, vol. 65, 69-93.

Galí, J., and M. Gertler, 1999, Inflation Dynamics: A Structural Econometric Analysis, Journal of Monetary Economics 44, 195-222

Galí, J., M. Gertler, and López-Salido, J.D., 2001,European Inflation Dynamics ,European Economic Review, vol. 45, 1237-1270.

Guerreri L., 2001, Inflation Dynamics, International Finance Discussion Papers, no. 715, Federal Reserve Board, Washington.

Glick, R. and Hutchison, M., 1994, Monetary policy, intervention, and exchange rates in Japan, in Glick and Hutchinson (eds.) Exchange Rate Policy and Interdependence: Perspectives from Pacific Basin, Cambridge UK: Cambridge University Press, 225-257.

Hannan, T. and Berger, A., 1991, The Rigidity of Prices: Evidence from the Banking Industry, American Economic Review, 81, 938-945.

Hutchison, M., 1988, Monetary Control with an Exchange Rate Objective: The Bank of Japan, 1973-1986, Journal of International Money and Finance, vol. 7, 261-271.

Hofmann, B., 2003, EMU and the Transmission of Monetary Policy: Evidence from Business Lending Rates, ZEI, University of Bonn.

Kueppers, M., 2001, Curtailing the Black Box: German Banking Groups in the Transmission of Monetary Policy, European Economic Review, vol. 45, 1907-1930.

Mayer, C., 1990, Financial Systems, Corporate Finance and Economic Development, in G. Hubbard (ed.), Information, Capital Markets and Investment, NBER.

Mojon, B., 2000. Financial Structure and the Interest Rate Channel of the ECB Monetary Policy, ECB Working Paper no. 40.

Ravenna, F., and C.E. Walsh, 2003, The Cost Channel in a New Keynesian Model: Evidence and Implications, University of California, Santa Cruz.

Sims, C.A., 1992, Interpreting the Macroeconomic Time Series Facts: The Effects of Monetary Policy, European Economic Review, vol. 36, 975-1000.

Woodford, M., 2001, The Taylor Rule and Optimal Monetary Policy, American Economic Review, Papers \& Proceedings 91, 232-237. 